\title{
Angiotensinogen T235 Expression is Elevated in Decidual Spiral Arteries
}

Terry Morgan, ${ }^{\ddagger}$ Catherine Craven, $\$$ Lesa Nelson, ${ }^{\S}$ Jean-Marc Lalouel, ${ }^{\star \ddagger}$ and Kenneth Ward $¥ \S$

*Howard Hughes Medical Institute, ${ }^{\ddagger}$ Department of Human Genetics, and ${ }^{\S}$ Department of Obstetrics and Gynecology, University of Utah Health Sciences Center, Salt Lake City, Utah 84112

\section{Abstract}

Preeclampsia is associated with a common molecular variant of angiotensinogen (Met235Thr). This variant is in tight linkage disequilibrium with a mutation in the angiotensinogen promoter, $G(-6) A$, which leads to elevated expression in vitro. Since angiotensin II levels could play a role in atherotic changes of the uterine spiral arteries associated with preeclampsia, we investigated angiotensinogen expression in the first trimester uterus. We localized angiotensinogen transcription in uterine decidua using in situ reverse transcription PCR. We then compared decidual T235 expression levels to M235 levels in heterozygous women using an allele-specific ligation assay and a single nucleotide primer extension assay. In human decidua, angiotensinogen is expressed only in spiral artery smooth muscle cells. Heterozygous women have significantly elevated expression of the T235 allele compared to the M235 allele $(P<0.0001)$. These observations suggest that elevated expression of the T235 allele in decidual spiral arteries may cause first trimester atherotic changes leading to preeclampsia. (J. Clin. Invest. 1997. 100:1406-1415.) Key words: preeclampsia • in situ RT-PCR • allele-specific expression

\section{Introduction}

Preeclampsia presents in the third trimester of pregnancy as the triad of hypertension, proteinuria, and edema. Pregnancies with increased placental mass (e.g., twins, hydrops) and relative reduction of placental perfusion are at increased risk of developing preeclampsia (1-4). Many investigators postulate that placental ischemia is an initiating event in the pathogenesis of this disease $(2,5,6)$. Accumulating evidence suggests that placental ischemia results in local metabolic changes (7) and the production of circulating factors that alter maternal endothelial function (8). Subsequently, endothelial injury initiates a cascade of coagulation, vasoconstriction, and fluid redistribution resulting in the clinical syndrome of preeclampsia.

In many pregnancies, reduced placental perfusion may be due to abnormal physiologic change of the uterine spiral arteries. Normally, pregnancy induces the uterine spiral arteries to remodel into dilated uteroplacental vessels by an unknown

Portions of this work have appeared in abstract form (1996. J. Soc. Gynecol. Invest. 3:447a); (1996. J. Soc. Gynecol. Invest. 3:486a).

Address correspondence to Kenneth Ward, M.D., Eccles Institute of Human Genetics, Room 2420, 2030 East 10 North Salt Lake City, Utah 84112. Phone: 801-585-6335; FAX: 801-581-7796.

Received for publication 4 December 1996 and accepted in revised form 16 July 1997.

J. Clin. Invest.

(C) The American Society for Clinical Investigation, Inc. 0021-9738/97/09/1406/10 \$2.00

Volume 100, Number 6, September 1997, 1406-1415

http://www.jci.org mechanism called physiologic change (9). In women who develop preeclampsia, however, spiral arteries appear to remodel abnormally, with vascular smooth muscle cell proliferation and atherosis (10-12).

Abnormal spiral artery remodeling appears to be a cause of preeclampsia, and not a consequence of the disease for a number of reasons. Spiral artery remodeling begins in the first trimester and is complete before clinical onset of preeclampsia $(13,14)$. Doppler ultrasound studies show that increased resistance to uteroplacental blood flow precedes preeclampsia (15, 16). Histologic studies using decidua from normal pregnancies terminated in the first trimester show that atherotic changes are present with the same relationship to parity as preeclampsia $(17,18)$. The cause of abnormal spiral artery remodeling is unknown.

We and others have used genetic analysis to identify candidate genes involved in the pathogenesis of preeclampsia. Preeclampsia appears to have a genetic component (19), and pedigree analysis suggests that it may be inherited as a singlegene disorder (20). We suspect that the angiotensinogen $(\mathrm{AGT})^{1}$ gene may have a role in preeclampsia (21). Studies of affected siblings have shown linkage between preeclampsia and a highly polymorphic dinucleotide repeat near the AGT gene (22). In our study population, $20 \%$ of caucasian women homozygous for the angiotensinogen T235 variant (Met235 $\rightarrow$ Thr235) develop preeclampsia, compared to $<1 \%$ of caucasian women homozygous for the protective M235 allele. While studies in Japan confirm this association $(21,23)$, a characteristic feature of studies in which statistical significance was not achieved is the low statistical power afforded by their small sample size (24).

We have sought a molecular mechanism to explain the statistical association between T235 and preeclampsia. Whether T235 directly accounts for a physiological effect or acts as a marker for another mutation is unresolved. We have, however, recently identified a mutation in the AGT promoter, A $(-6)$, which is in very tight linkage disequilibrium with T235 (25). Women with the $\mathrm{A}(-6)$ promoter mutation almost always have the T235 allele. Conversely, only $1 \%$ of the women with the T235 allele lack the $A(-6)$ promoter mutation. Our in vitro studies suggest that the $\mathrm{A}(-6)$ promoter mutation may cause elevated T235 expression in vivo (25).

Elevated angiotensinogen T235 expression may play a role in atherotic changes leading to preeclampsia. AGT is the precursor peptide of the vasoactive hormone angiotensin II, which plays a role in vascular remodeling (26-28), and is a potent vascular smooth muscle cell mitogen (29-32). In addition to the classical circulating renin-angiotensin system (RAS), there are local de novo systems generating local angiotensin II (26). Since the renin-angiotensinogen reaction is the rate-limiting step in the generation of angiotensin II, any abnormal elevation in local AGT expression would lead to abnormally

1. Abbreviations used in this paper: AGT, angiotensinogen gene; RAS, renin-angiotensin system; RT-PCR, reverse transcription polymerase chain reaction; $\mathrm{SNuPE}$, single nucleotide primer extension. 
high local angiotensin II levels (33). Elevated angiotensin II levels appear to play a role in atherotic change in other tissues $(27,28)$; therefore, we hypothesize that AGT expression may be elevated in the spiral arteries of women carrying the T235 allele.

To test this hypothesis, we localized AGT expression in first trimester decidua using in situ reverse transcription PCR (RT-PCR) (34). We then compared T235 expression to M235 levels using an allele-specific ligation assay (35) and a single nucleotide primer extension assay (36).

\section{Methods}

Samples. Using a protocol approved by the University of Utah Institutional Review Board, we obtained products of conception from normal first and second trimester pregnancies, which were electively terminated at the Utah Women's Clinic. We collected 60 samples of maternal decidua and the corresponding fetal-placental villi (5-13 wk gestation). The decidual tissue was obtained immediately after disruption. Efforts were made to collect grossly intact nonnecrotic decidua, but the exact position of the sample in relation to the placental bed was unknown. We also collected 14 fetal livers (15-20 wk gestation). The fetal livers were used as positive controls for AGT expression. Tissue samples were split into two pieces: one portion was snap frozen in liquid nitrogen to preserve the RNA, and the second portion was fixed in cold buffered formalin for in situ studies (37) and for routine histology (38). Maternal venous blood drawn for pregnancy testing was obtained to determine the mother's genotype.

Nucleic acid preparation. Maternal genomic DNA was extracted from whole blood (Puregene System; Gentra Systems, Inc., Research Triangle Park, NC). Total RNA and genomic DNA was prepared from maternal decidua, fetal villi, and fetal liver homogenates using TRI-REAGENT ${ }^{\mathrm{TM}}$ (Molecular Res. Ctr., Inc., Cincinnati, OH) according to manufacturer's instructions (39). Messenger RNA was extracted from total RNA using mRNA Separator columns (Clontech, Palo Alto, CA).

Angiotensinogen M235T genotyping. Maternal and fetal DNA was genotyped for the T235/M235 polymorphism by mutagenically separated PCR (MS-PCR) (40, 41). MS-PCR was performed using two different allele-specific upstream primers and a common downstream primer (AGTint2: 5' AGC AGA GAG GTT TGC CTT ACC $\left.\mathrm{T} 3^{\prime}\right)$ from AGT intron 2. The upstream primers were as follows: $(a)$ AGT-M235, 5' GTT CAT GCA GGC TGT GAC AGC TTG GAA GAC TGG CTG CTC CCT CAT 3', whose 3'-nucleotide anneals to the M235 polymorphic site (ATG); and (b) AGT-T235, 5' GAT GGA AGA CTG GCT GCT CCC AGA C 3', whose 3'-nucleotide anneals to the T235 polymorphic site (ACG). The AGT-M235-specific primer was designed to be 20 nucleotides longer than the AGTT235 primer. Thus, AGT M235 homozygotes generated a 118-base pair product, T235 homozygotes generated a 98-base pair product, and M235/T235 heterozygotes generated both a 118- and a 98-base pair product. Amplification was done in a final volume of $25 \mu \mathrm{l}$, and included the following: $300 \mathrm{ng}$ of genomic DNA, $10 \mathrm{mM}$ Tris- $\mathrm{HCl}, \mathrm{pH}$ 8.4, $40 \mathrm{mM} \mathrm{NaCl}, 1.5 \mathrm{mM} \mathrm{MgCl} 2,0.5 \mu \mathrm{M}$ AGT-Int2, $0.5 \mu \mathrm{M}$ AGTT235, $0.33 \mu \mathrm{M}$ AGT-M235, $0.25 \mathrm{mM}$ spermidine, $200 \mu \mathrm{M}$ dNTPs, and 0.625 units Taq polymerase (Perkin-Elmer Corp., Norwalk, CT). Reactions were denatured at $94^{\circ} \mathrm{C}$ for $5 \mathrm{~min}$, followed by 36 cycles of $94^{\circ} \mathrm{C}(30 \mathrm{~s}), 61^{\circ} \mathrm{C}(30 \mathrm{~s})$, and $72^{\circ} \mathrm{C}(30 \mathrm{~s})$ (Techne $\mathrm{PH}-3$ thermal cycler; Techne, Duxford, United Kingdom). The MS-PCR products were visualized by ethidium bromide staining after electrophoretic fractionation through a 5\% 3:1 NuSieve:Seakem agarose (FMC Bioproducts, Rockland, ME) gels. Controls were sequenced to confirm genotype.

Maternal decidual tissues from AGT heterozygotes $(n=39)$ were used to compare T235 levels to M235 levels by allele-specific expression analysis. Decidua and fetal liver from AGT homozygotes (15 decidua: 14 MM, 1 TT; 2 fetal liver: 1 MM, 1 TT) were used as controls in the allele-specific analysis.
Angiotensinogen $G(-6)$ A genotyping. Maternal DNA was genotyped for the G(-6)A transition by MS-PCR (40, 41). MS-PCR was performed using two different allele-specific downstream primers and a common upstream primer (AGT-6MS5', GTG TCG CTT CTG GCA TCT GTC CTT CTG G) designed from the AGT promoter. The downstream primers were designed as follows: (a) AGT-6MS 3'S, TA CCC AGA ACA ACG GCA GCT TCT TCC ACT, whose $3^{\prime}$ nucleotide anneals to the $\mathrm{A}(-6)$ polymorphic site; and $(b)$ AGT -6MS3'L, C CGG TTA CCT TCT GCT GTA GAG CCC AGA ACA ACG GCA GCT TCT TCC ATC, whose 3' nucleotide anneals to the $\mathrm{G}(-6)$ polymorphic site. A $(-6)$ homozygotes generated a $187-$ base pair product, $\mathrm{G}(-6)$ homozygotes generated a 212-base pair product, and heterozygotes generated both products. Amplification was done in a final volume of $20 \mu \mathrm{l}$, and included the following: 300 ng of genomic DNA, $10 \mathrm{mM}$ Tris- $\mathrm{HCl}, \mathrm{pH} 8.4,40 \mathrm{mM} \mathrm{NaCl}, 1.5 \mathrm{mM}$ $\mathrm{MgCl}_{2}, 0.1 \mu \mathrm{M}$ AGT-6MS5', $0.1 \mu \mathrm{M}$ AGT-6MS 3'S, $0.4 \mu \mathrm{M}$ AGT $-6 \mathrm{MS3}{ }^{\prime} \mathrm{L}, 0.25 \mathrm{mM}$ spermidine, $200 \mu \mathrm{M}$ dNTPs, and $0.625 \mathrm{U}$ Taq polymerase (Perkin-Elmer Corp.). Reactions were denatured at $94^{\circ} \mathrm{C}$ for $5 \mathrm{~min}$, followed by 36 cycles of $94^{\circ} \mathrm{C}(30 \mathrm{~s}), 59^{\circ} \mathrm{C}(30 \mathrm{~s})$, and $72^{\circ} \mathrm{C}$ (30 s) on a Techne PH-3 thermal cycler (Techne). The MS-PCR products were visualized by ethidium bromide staining after electrophoretic fractionation through 5\% 3:1 NuSieve:Seakem agarose gels. Controls were sequenced to confirm genotype.

Angiotensinogen A(-20)C genotyping. Maternal DNA was genotyped for the A(-20)C transversion by MS-PCR (40, 41). MS-PCR was performed using two different allele-specific upstream primers and a common downstream primer AGT-20MS3': ACC TTC TGC TGT AGT ACC CAG, designed from AGT exon 1. The upstream primers were designed as follows: (a) AGT-20MS 5'S, CAC CCC TCA GCT ATA AAT AGG CCC, whose 3 ' nucleotide anneals to the $\mathrm{C}(-20)$ polymorphic site; and $(b)$ AGT-20MS3'L, CCT GGG AAC AGC TCC ATC CCG TCC CCT CAG CTA TAA ATA GCG $\mathrm{CA}$, whose $3^{\prime}$ nucleotide anneals to the $\mathrm{A}(-20)$ polymorphic site. $\mathrm{C}(-20)$ homozygotes generated a $82-$ base pair product, $\mathrm{A}(-20)$ homozygotes generated a 102-base pair product, and heterozygotes generated both products. Amplification was done in a final volume of $25 \mu \mathrm{l}$, and included the following: $300 \mathrm{ng}$ of genomic DNA, $10 \mathrm{mM}$ Tris- $\mathrm{HCl}, \mathrm{pH} 8.4,40 \mathrm{mM} \mathrm{NaCl}, 1.5 \mathrm{mM} \mathrm{MgCl}_{2}, 0.5 \mu \mathrm{M}$ AGT-20MS3', $0.5 \mu \mathrm{M}$ AGT-20MS 5'S, $0.17 \mu \mathrm{M}$ AGT-20MS3'L, $0.25 \mathrm{mM}$ spermidine, $200 \mu \mathrm{M}$ dNTPs, and $0.625 \mathrm{U}$ Taq polymerase (Perkin-Elmer Corp.). Reactions were denatured at $94^{\circ} \mathrm{C}$ for $5 \mathrm{~min}$, followed by 35 cycles of $94^{\circ} \mathrm{C}(10 \mathrm{~s}), 55^{\circ} \mathrm{C}(10 \mathrm{~s})$, and $72^{\circ} \mathrm{C}(10 \mathrm{~s})$ on a GeneAmp 9600 thermocycler (Perkin-Elmer Corp.). The MS-PCR products were visualized by ethidium bromide staining after electrophoretic fractionation through 5\% 3:1 NuSieve:Seakem agarose gels. Controls were sequenced to confirm genotype.

$R T-P C R$. We selected primers designed from angiotensinogen exon 2:AGT-Ex2, 5' ACT TCA CAG AAC TGG ATG TTG CTG C 3'; and exon 3: AGT-Ex3, 5'AAC AGA CAC TGA GGT GCT GTT GTC CAC 3'. These primers flank intron $2(6.4 \mathrm{~kb})$, and did not amplify genomic DNA. In each experiment, $300 \mathrm{ng}$ of total RNA from fetal liver served as a positive control for AGT mRNA. Water blanks were used to detect contamination. $300 \mathrm{ng}$ of total RNA from decidual samples were used as a template for reverse transcription. For the purpose of presentation, we also tested $100 \mathrm{ng}$ of mRNA prepared from three decidual samples $(7,10$, and $13 \mathrm{wk}$ gestation $)$ and one fetal liver sample (19 wk). Reverse transcription was performed as follows: RNA samples were mixed with 5.0 U rTth polymerase (Perkin-Elmer Corp.), $0.75 \mu \mathrm{M}$ downstream primer AGT-Ex3, $200 \mu \mathrm{M}$ dNTPs, $1 \mathrm{mM}$ $\mathrm{MnCl}_{2}$, and $1 \mathrm{X}$ rTth Reverse Transcriptase Buffer (Perkin-Elmer Corp.) in a total volume of $20 \mu \mathrm{l}$. The samples were incubated for 15 min at $65^{\circ} \mathrm{C}$ to reverse transcribe AGT mRNA into cDNA, then PCR-amplified as follows: the $20 \mu \mathrm{l}$ reverse transcription reaction was expanded to $100 \mu \mathrm{l}$ by adding upstream primer AGT-Ex2 (final concentration $0.15 \mu \mathrm{M}$ ), $\mathrm{MgCl}_{2}$ (final concentration $2.0 \mathrm{mM}$ ), and chelating buffer (final concentration $0.8 \times$ ) to chelate the $\mathrm{Mn}++$. The cDNA was amplified using a GeneAmp 9600 thermocycler (PerkinElmer Corp.): $1 \mathrm{~min}$ at $94^{\circ} \mathrm{C}$, then 35 cycles of $10 \mathrm{~s}$ at $94^{\circ} \mathrm{C}$, and $15 \mathrm{~s}$ at 
$60^{\circ} \mathrm{C}$. The 202-bp RT-PCR product was visualized by ethidium bromide staining after electrophoretic fractionation through $5 \% \quad 3: 1$ NuSieve:Seakem agarose gels. RT-PCR products from one liver and one decidual sample were sequenced to confirm reaction specificity.

In situ RT-PCR. We performed the in situ studies using the methods of Wilcox (37) and Nuovo (34). Decidual cryosections (8 $\mu \mathrm{m})$ were cut and placed on silane-treated slides (Cel-line Associates, Inc., Newfield, NJ), which have three wells per slide with one section in each well. After sectioning, samples were refixed in ice-cold $4 \%$ paraformaldehyde (J.T. Baker, Inc., Phillipsburg, NJ), buffered in PBS, $\mathrm{pH} 7.4$, for 2-3 h, rinsed in PBS, proteinase $\mathrm{K}$ (Boehringer Mannheim Biochemicals, Indianapolis, IN), digested $(6 \mu \mathrm{g} / \mathrm{ml}$ in PBS) for 3 $\mathrm{min}$, rinsed, and refixed for 15 more $\min$ in $4 \%$ paraformaldehyde. Sections were then dehydrated in ethanol and either used immediately or stored at $-70^{\circ} \mathrm{C}$. Reverse transcription was done using a Perkin Elmer 480 thermocycler (Perkin-Elmer Corp.). After reverse transcription, slides were washed for $5 \mathrm{~min}$ in Xylene followed by $5 \mathrm{~min}$ in $100 \%$ ethanol. Each section was then incubated with a $20-\mu l$ reaction mix containing $4.5 \mathrm{mM} \mathrm{MgCl}_{2}, 2 \% \mathrm{BSA}, 5 \mathrm{U}$ Taq polymerase, $1 \mu \mathrm{M}$ AGT-Ex2 and $1 \mu \mathrm{M}$ AGT-Ex3, $200 \mu \mathrm{M}$ dNTPs, $10 \mu \mathrm{M}$ digoxigenin dUTP, and $1 \times$ PCR buffer (Perkin-Elmer Corp.). cDNA was amplified as follows: $1 \mathrm{~min}$ at $94^{\circ} \mathrm{C}$, then 20 cycles of $1 \mathrm{~min}$ at $94^{\circ} \mathrm{C}$ and $2 \mathrm{~min}$ at $55^{\circ} \mathrm{C}$. The digoxigenin-labeled RT-PCR product was detected using an alkaline phosphatase-conjugated antidigoxigenin antibody (Boehringer Mannheim Biochemicals), visualized by adding the substrates nitro blue tetrazolium and 5-bromo-4 chloro-3 indoylphosphate. Sections were counterstained with eosin, and photographed (Optiphot-2; Nikon Inc., Melville, NY).

In situ RT-PCR controls. Positive and negative control reactions were performed on the same glass slide as the test reaction (34). The purple signal in the positive control represents amplification of genomic DNA as well as cDNA, and is predominantly found in the nucleus. The negative control well was DNAse-treated overnight with a RNAse-free DNAse solution according to the manufacturer's recommendations (10 U/section, $37^{\circ} \mathrm{C}$, Boehringer Mannheim Biochemicals), and it was not reverse transcribed. The negative control lacks signal, and only the red counterstain is observed. The test section was DNAse-treated like the negative control, but it was reverse transcribed for $30 \mathrm{~min}$ using the reaction mix described in the RT-PCR section. In situ RT-PCR of vimentin mRNA was performed on serial sections as a positive control for an abundant transcript, and to show signal specificity using vimentin-specific primers: VIM2 (exon2), AGA GAG GAA GCC GAA AGC ACC CTG CAA; VIM3 (exon3), GTC AGC AAA CTT GGA CTT GTA CCA TTC. Primer sets spanned large introns, and only amplified cDNA.

Immunohistochemistry. To investigate whether the angiotensinogen protein could also be localized in human decidua, we stained paraffin-embedded sections of first trimester decidual samples using an antihuman angiotensinogen polyclonal antibody (1:200), kindly provided by Duane Tewksbury (Marshfield Medical Research Foundation, Marshfield, WI). To determine whether the cells expressing AGT mRNA were spiral artery smooth muscle cells, we stained serial cryosections of the tissue used for in situ RT-PCR for $\alpha$-smooth muscle cell actin (1:50; Dako Corp., Carpinteria, CA). To determine whether invading fetal trophoblasts express AGT, we stained serial cryosections of the tissue used for in situ RT-PCR for invasive fetal trophoblasts using a monoclonal antibody against low molecular weight cytokeratin (1:200; Dako Corp.). Immunostaining was performed according to routine methods as suggested by the manufacturer (Dako Corp.). In brief, sections were blocked with 3\% blocking reagent (Boehringer Mannheim Biochemicals), incubated with the appropriate primary antibody, and then incubated with biotinylated anti-mouse/anti-rabbit secondary antibodies (Dako Corp.). Sections were then labeled with streptavidin conjugated to horseradish peroxidase, and were visualized with 3-amino-9-ethyl-carbazole (Sigma Chemical Co., St. Louis, MO), counterstained with Mayer's hematoxylin, and photographed (Optiphot-2).

Allele-specific assays. To compare T235 expression levels to
M235 levels we used the ligation assay as first described by Powell et al. (35) and confirmed these results by a second assay, the single nucleotide primer extension assay (36).

Template purification. AGT cDNA template was prepared by RT-PCR amplification of AGT transcript in total RNA of maternal decidual and fetal liver samples. Genomic DNA template was also prepared to serve as an internal control: $(a)$ to confirm AGT genotype, and $(b)$ to confirm that the allele-specific expression assays show the expected 1:1 ratio of T235:M235 genomic signal in heterozygous samples (42). Genomic DNA PCR template was prepared as follows: genomic DNA was amplified using the AGT Ex2-AGTint2 primer set (described above), which also flanks the T235/M235 polymorphism. Template was extracted with phenol-chloroform, and was precipitated with ethanol. The template was then gel purified using low-melting agarose (FMC Bioproducts) and the Mermaid system (Bio 101, La Jolla, CA) according to manufacturer's instructions. Template was resuspended in 10-20 $\mu$ l of $10 \mathrm{mM}$ Tris- $\mathrm{HCl}, \mathrm{pH} 8.0$, and $1 \mathrm{mM}$ EDTA at $20 \mathrm{pmole} / \mu \mathrm{l}$.

Ligation assay. A common 20-bp $\gamma$-32P-labeled oligo (T235LigCP3: 5' TCA GGG AGC AGC CAG TCT TC 3') and two different-sized allele-specific primers (T235-LigA3, specific to T235 allele, 18mer: 5' TGT CCA CAC TGG CTC CCG 3'; and M235-LigB3, specific to M235 allele, 21mer: 5' TGC TGT CCA CAC TGG CTC CCA $\left.3^{\prime}\right)$ were used in the ligation assay. Each ligation reaction was carried out in a $25 \mu \mathrm{l}$ volume containing 0.025 pmoles of template, 0.25 pmoles of the common primer, and M235-specific primer, 0.25 pmoles of T235 primer (empirically determined to yield 1:1 ratio on genomic controls), $5 \mathrm{U}$ of Ampligase (Epicentre Technologies Corp., Madison, WI), and $1 \times$ Ampligase buffer (Epicentre Technologies Corp.). Samples were subjected to one cycle of ligation by heating the sample to $94^{\circ} \mathrm{C}$ for $2 \mathrm{~min}$, then incubating at 55 degrees for $3 \mathrm{~min}$ on a Techne PH-3 thermal cycler (Techne). The products were electrophoretically separated by $15 \%$ PAGE and the amount of $\gamma^{3}{ }^{32} \mathrm{P}$ radioactivity incorporated in the M235-specific band (41 bp), and the T235-specific band (38 bp) was quantitated by densitometry using a PhosphorImager (Molecular Dynamics, Inc., Sunnyvale, CA). Reactions and measurements were repeated three times. Samples exhibiting dramatically elevated T235 levels were reextracted, and the assay was repeated.

Single nucleotide primer extension ( $S N u P E$ ) assay. To determine whether results obtained using the ligation assay were reproducible using a second method, we tested the samples using SNuPE (36). We used a common primer (AGT-SNuPE: AAG ACT GGC TGC TCC CTG A), which anneals one base pair upstream of the polymorphic $\mathrm{C}$ to $\mathrm{T}$ transition $(\mathrm{T} 235=\mathrm{ACG}$; $\mathrm{M} 235=\mathrm{ATG})$, and two separate reaction tubes. In one tube we added $\left[\alpha^{32} \mathrm{P}\right] \overline{\mathrm{d}} \mathrm{CTP}$; in the second tube we added $\left[\alpha^{32} \mathrm{P}\right] \mathrm{dTTP}$. After electrophoresis, we quantified relative $\left[\alpha^{32} \mathrm{P}\right] \mathrm{dCTP} /\left[\alpha^{32} \mathrm{P}\right] \mathrm{dTTP}$ incorporation by densitometry. TT homozygotes should exhibit $\left[\alpha^{32} \mathrm{P}\right] \mathrm{dCTP}$ signal and no $\left[\alpha^{32} \mathrm{P}\right] \mathrm{dTTP}$ signal. MM homozygotes should exhibit $\left[\alpha^{32} \mathrm{P}\right] \mathrm{dTTP}$ signal and no $\left[\alpha^{32} \mathrm{P}\right] \mathrm{dCTP}$ signal. Heterozygotes should show both $\left[\alpha^{32} \mathrm{P}\right] \mathrm{dTTP}$ and $\left[\alpha^{32} \mathrm{P}\right] \mathrm{dCTP}$. We tested the genomic DNA and cDNA template prepared for the ligation assay. For each template, the master mix contained the following in a total volume of $18 \mu \mathrm{l}: 10 \mathrm{ng}$ template, $10 \mathrm{mM}$ Tris- $\mathrm{HCl}, \mathrm{pH} 8.3,50 \mathrm{mM} \mathrm{KCl}, 1.5 \mathrm{mM} \mathrm{MgCl}_{2}, 1 \mu \mathrm{M}$ AGT-SNuPE primer, and $0.75 \mathrm{U}$ Taq polymerase (Perkin-Elmer Corp.). The master mix was separated into two reaction tubes as follows: $9 \mu \mathrm{l}$ into a tube containing $1 \mu \mathrm{l}$ of $\left[\alpha^{32} \mathrm{P}\right] \mathrm{dCTP}(3,000 \mathrm{Ci} / \mathrm{mmol}, \mathrm{NEN}$ Research Products, Boston, MA) diluted 10-fold, and $9 \mu \mathrm{l}$ into a tube containing $1 \mu \mathrm{l}$ of $\left[\alpha^{32} \mathrm{P}\right] \mathrm{dTTP}(3,000 \mathrm{Ci} / \mathrm{mmol}, \mathrm{NEN})$ diluted 10 -fold. The reactions were incubated at $95^{\circ} \mathrm{C}$ for $1 \mathrm{~min}, 50^{\circ} \mathrm{C}$ for $2 \mathrm{~min}$, and $72^{\circ} \mathrm{C}$ for $1 \mathrm{~min}$ for one cycle in a GeneAmp 9600 thermocycler (Perkin-Elmer Corp.). The products were electrophoretically separated by $15 \%$ PAGE, and the amount of radioactivity incorporated in the $\left[\alpha^{32} \mathrm{P}\right] \mathrm{dCTP}$ and $\left[\alpha^{32} \mathrm{P}\right] \mathrm{dTTP}$ reactions were quantitated by densitometry using a PhosphorImager (Molecular Dynamics Inc.).

Allele-specific expression controls. We tested controlled mixtures of total RNA extracted from the livers of a TT and MM ho- 
mozygous fetus in allele-mixing experiments (100\% MM, 10:1, 5:1, $2: 1,1: 1,1: 2,1: 5,1: 10,100 \%$ TT). These experiments served to measure background and to determine the accuracy of the ligation and SNuPE assays.

Fetal contamination controls. To investigate whether invading placental trophoblasts express AGT and alter maternal allele-specific expression ratios, we tested 15 decidual samples prepared from homozygous women (14 MM, 1 TT) carrying a heterozygous fetus (TM). If the fetal cells made contaminating AGT, we would expect contaminating fetal signal in the decidual RNA (eg., T235 signal in a decidual sample from a MM homozygous woman). We also examined fetal trophoblasts in decidual sections showing AGT signal in vessels by in situ RT-PCR. We confirmed that trophoblasts were present in the section by staining serial sections for low molecular weight cytokeratin (43).

Statistical analysis. We compared the average T235/M235 ratio observed in the cDNA to the T235/M235 ratio observed in the genomic DNA for each sample using the nonparametric Wilcoxon Signed Rank Test (44). Since the variance increased with the mean allele-specific signal, we also analyzed the data after stabilizing this variance by taking the log of the raw values. We compared $\log (\mathrm{T} 235) /$ $\log$ (M235) in the cDNA to $\log (\mathrm{T} 235) / \log$ (M235) in the genomic DNA controls using the nonparametric Wilcoxon Signed Rank Test. To determine whether elevated T235 signal observed in the cDNA could be due to fetal contamination, we used the Fisher's Exact Test (44) to compare the frequency of heterozygous samples showing elevated T235 levels to the frequency of contaminating fetal signal in homozygous samples. We also tested for an association between elevated T235 expression and fetal genotype, the $\mathrm{C}(-20)$ AGT promoter variant, and maternal race using the Kruskal-Wallis Test (44). We used simple regression analysis to evaluate allele-mixing experiments, to compare results obtained by the two assays, and to test for an association between elevated T235 expression and gestational age, parity, and maternal age (44).

\section{Results}

AGT is expressed in maternal decidua. All decidual extracts tested by RT-PCR yielded an AGT-specific product of expected size (Fig. 1) and sequence (data not shown). Angiotensinogen mRNA was not detected on Northern blots, or by conventional in situ hybridization (data not shown), suggesting that decidual AGT is expressed at low levels, consistent with a local RAS (45).

Expression is localized to spiral artery smooth muscle cells. In situ RT-PCR localized expression of the AGT transcript to spiral artery smooth muscle cells (Fig. 2, $A-C$ ). The purple signal in the positive control represented amplification of genomic DNA as well as cDNA, and was predominantly found in the nucleus. After DNAse treatment and without reverse transcription, the negative control lacked signal, and only the red counterstain was observed. The test section, which was DNAse-treated and reverse transcribed, showed purple signal in the cytoplasm of spiral artery smooth muscle cells. Only a faint background signal was seen in the extra cellular matrix and decidual stroma. Positive cells were confirmed to be smooth muscle cells by the presence of $\alpha$-smooth muscle cell actin staining in serial sections. In situ RT-PCR reactions appeared to be specific, because when we used control primers designed to amplify vimentin mRNA rather than AGT mRNA, we observed the expected mesenchymal expression pattern rather than signal localized solely to the vessel wall (Fig. 2, $D-F$ ). We did not detect AGT expression in any of the fetal trophoblasts identified by immunohistochemistry in serial sections. Fig. 3 is an example of one of these trophoblasts

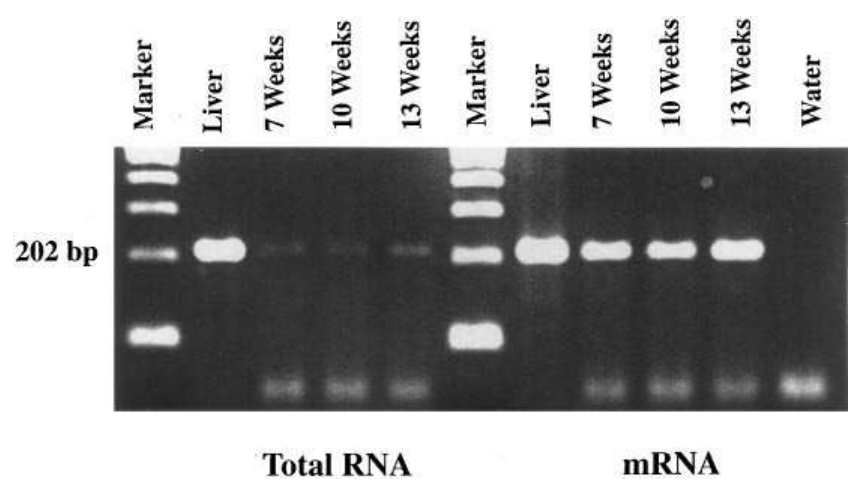

Figure 1. Angiotensinogen is transcribed in human decidua. RT-PCR amplification of total RNA (300 ng) and mRNA (100 ng) prepared from fetal liver (19 wk gestation) and decidua (7, 10, and 13 wk gestation). Water served as the negative control. The RT-PCR product is expected size (202 bp) and sequence (data not shown).

present in the decidual sample shown in Fig. 2. AGT protein was detected in the spiral artery lumen, consistent with circulating AGT in maternal plasma, but was not obviously present in the wall of these vessels (data not shown). This is not surprising, because local renin-angiotensin systems are present at low levels (45).

Allele-mixing controls. The accuracy of allele-specific ligation assay and the single nucleotide primer extension assay was determined using allele-mixing experiments. RNA from two fetal liver samples (TT homozygote and MM homozygote) were mixed in defined ratios: RT-PCR amplified and analyzed. The observed ratios $(\mathrm{T} / \mathrm{M})$ correlated well with the expected ratios for the ligation assay $(r=0.998)$ (Fig. 4) and the SNuPE assay ( $r=0.987$ ) (Fig. 5). Background was reproducibly $<10 \%$ of total signal, consistent with previously reported values for these assays $(35,36)$.

AGT T235 expression is elevated in maternal decidua. We used two assays to test the hypothesis that T235 expression is elevated compared to M235 levels in first trimester decidua from heterozygous mothers. Examples of results obtained using the ligation assay and the SNuPE assay are illustrated in Figs. 6 and 7, respectively. The T235/M235 signal ratio was significantly increased in the cDNA compared to the genomic DNA controls using either the ligation assay $(P<0.0001)$ or the SNuPE assay $(P<0.01)$ (Table I). The two assays showed a positive correlation $(r=0.85, P<0.0001)$ (Table II), suggesting that differences in allele-specific signal resulted from differences in allele-specific expression. We observed increasing variance with increasing mean allele-specific signal; therefore, we stabilized the variance by taking the log of the raw data and repeated the analysis. Even after this rigorous transformation, we observed a significant increase in T235 signal in the cDNA using the ligation assay $(P<0.0001)$ and the SNuPE assay $(P<0.05)$.

Although any cutoff is arbitrary given the continuous distribution observed in our sample population, the twofold cutoff is commonly referred to in the literature $(35,36)$. Results obtained using both the ligation and SNuPE assays show that between $25-40 \%(10 / 39-15 / 39)$ of first trimester decidual samples exhibit at least a twofold increase in T235 levels compared to M235 expression (Table II). None (0/39) of the samples demonstrated at least a twofold decrease in T235 levels when 


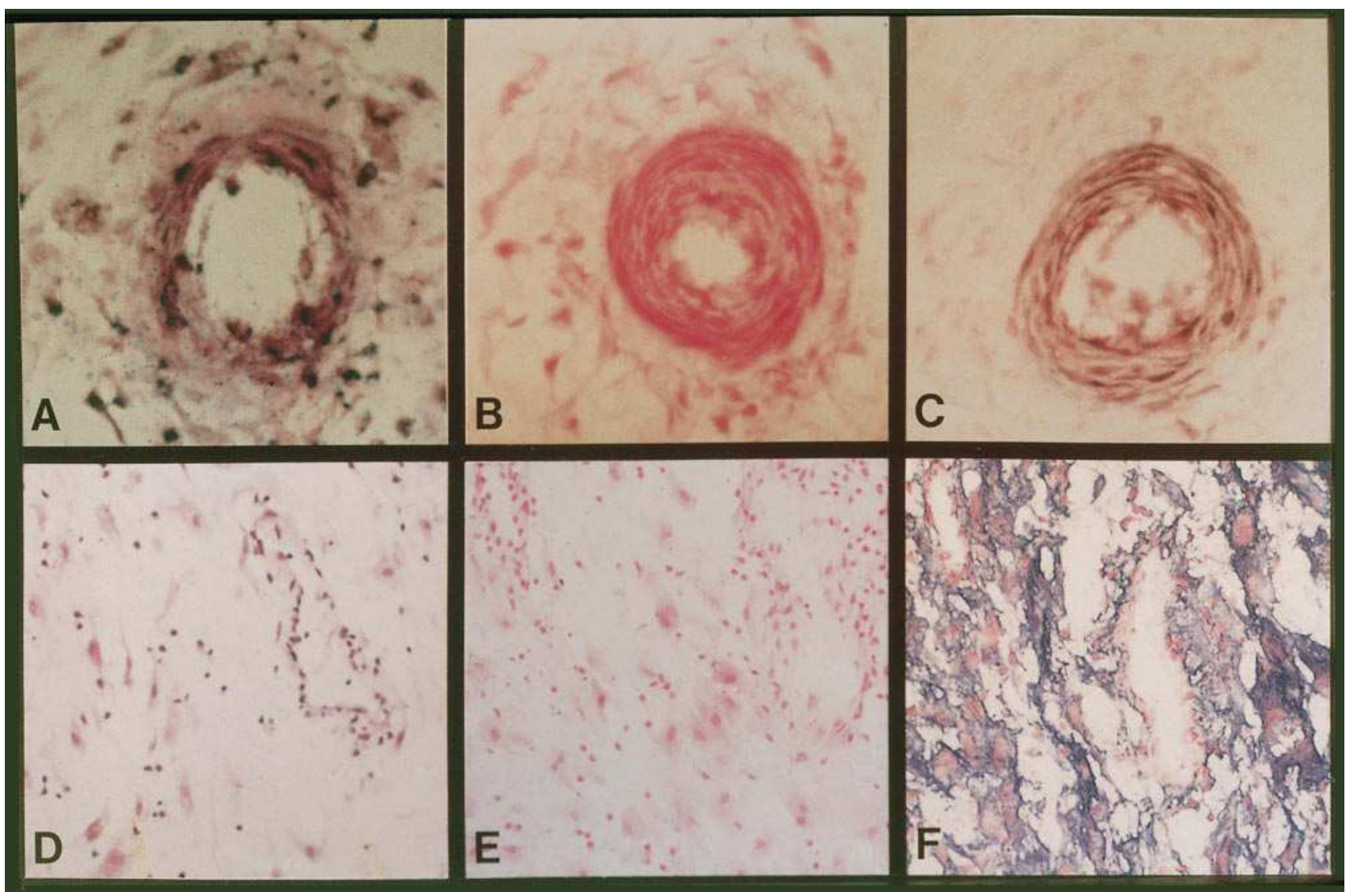

Figure 2. In situ RT-PCR specifically amplified AGT mRNA. (A) Positive control section was not DNAse-treated before in situ RT-PCR using AGT-specific primers. Nuclei are labeled purple. $(B)$ Negative control was DNAse-treated and not reverse transcribed. No purple signal is evident in spiral artery smooth muscle cells after PCR using AGT primers. (C) Test section was DNAse-treated, and then reverse transcribed before PCR. Purple signal represents amplified AGT mRNA in spiral artery smooth muscle cells. $(D)$ Vimentin positive control. Nuclei are labeled purple. $(E)$ Vimentin negative control. No purple signal is evident in mesenchymal stroma. $(F)$ Vimentin test section using vimentin-specific primers shows staining in mesenchymal stromal cells sparing epithelial glands, suggesting that in situ RT-PCR reactions are specific. Sections were counterstained with eosin. Original magnifications: $A-C, \times 400 ; D-F, \times 200$.

compared with M235 expression. Genomic DNA controls showed little departure from the 1:1 ratio. The fact that not all heterozygous women exhibit at least a twofold increase in T235 expression when compared with M235 levels may reflect continuous variability around the mean effect of the $A(-6)$ mutation, or it may point to the contribution of an additional discrete factor(s) required to mediate this genetic effect.

Examined heterogenous effects on allele-specific expression. We tested numerous possibilities for an association between discrete genetic factors and elevated T235 expression in

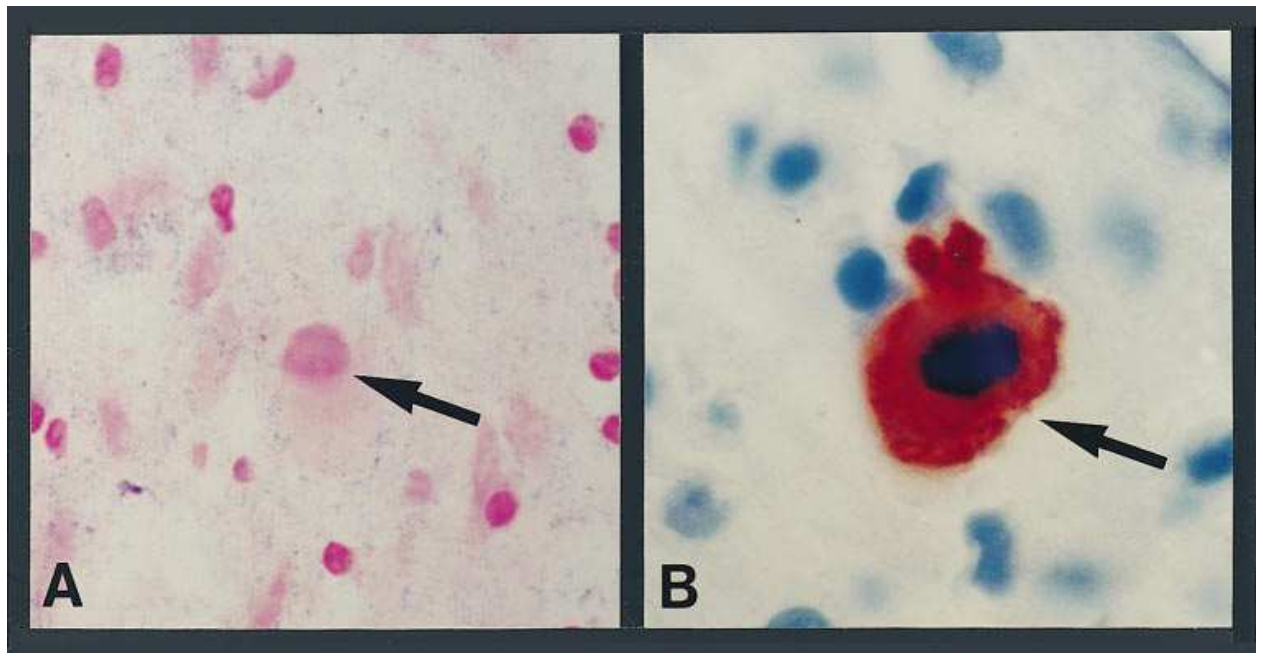

Figure 3. (A) Fetal trophoblast in decidual section tested for AGT expression by in situ RT-PCR. Although faint background signal can be seen in surrounding extracellular matrix, fetal trophoblast (arrow) did not stain for AGT expression. (B) Serial section stained for cytokeratin and counterstained with Mayer's Hematoxylin confirmed that the negative cell is a fetal trophoblast (arrow). Original magnifications: $\times 1510$. 

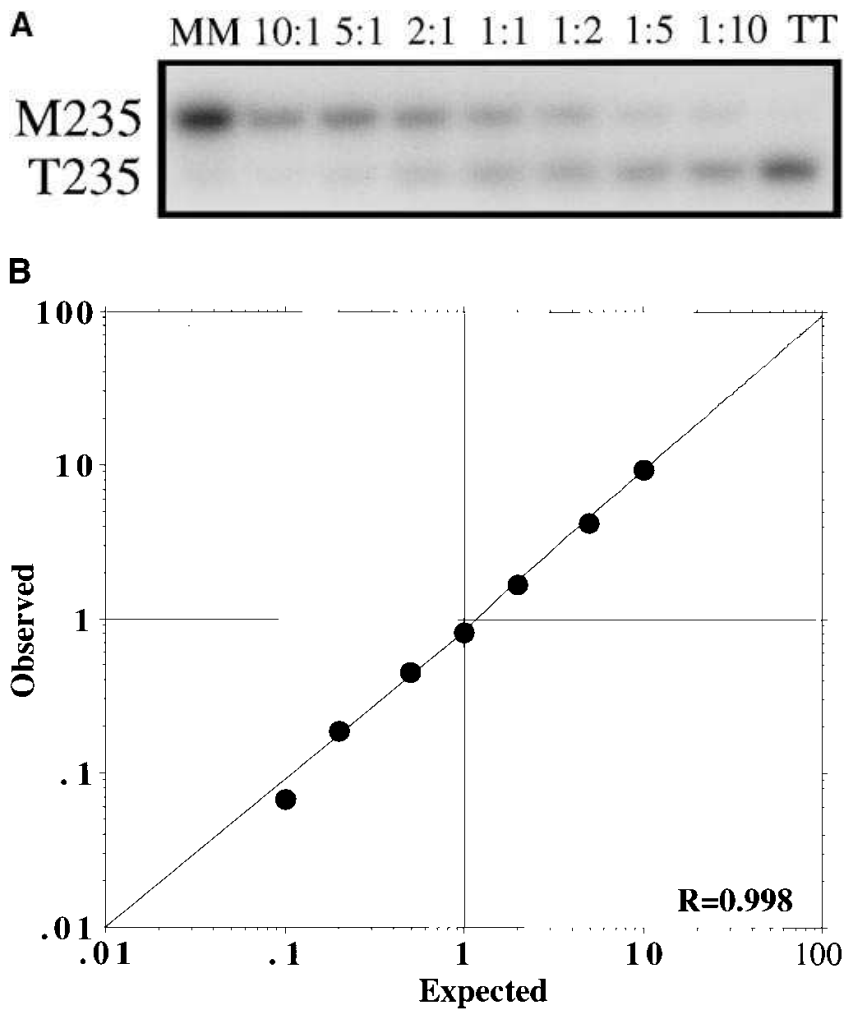

Figure 4. Allele-mixing analysis to determine the accuracy of the allele-specific ligation assay. Defined amounts of RNA from two homozygous fetal liver samples (TT or MM at amino acid 235) were used as templates for RT-PCR amplification and subsequent ligation reactions. The expected ratio is based on the relative amount of each allele added to the assay. $(A)$ The autoradiogram demonstrates that signal is a function of relative allele representation (T235:M235).

$(B)$ The regression plot below the autoradiogram shows the mean of three experiments. A strong positive correlation between the expected T235/M235 ratio and the observed T235/M235 ratio ( $r=$ 0.998) demonstrates the accuracy of the ligation assay.

our sample population. Since all 39 samples shared the same $\mathrm{G}(-6)$ A genotype (Table II), we considered the possibility that a different AGT promoter mutation may affect AGT expression. We tested the hypothesis that elevated T235 expression may be associated with the $\mathrm{C}(-20)$ variant in the AGT promoter (40). A discrete subset (40\%) of individuals with the T235 allele also have the $C(-20)$ variant promoter (40). If differences at the -20 locus cause elevated T235 expression compared to M235 levels, we would expect equal allele-specific levels in the decidual samples from $\mathrm{C}(-20)$ and $\mathrm{A}(-20)$ homozygous women. Similarly, we expect elevated T235 levels in women heterozygous at the $\mathrm{C}(-20) \mathrm{A}$ locus. Contrary to this hypothesis, however, we observed that decidual samples from women heterozygous at -20 were not more likely to show elevated T235 signal by either the ligation assay $(P=0.18)$ or the SNuPE assay $(P=0.19)$ (Table II). Although we may not have sufficient power to detect subtle heterogenous effects, we also ruled out gestational age $(P=0.12)$, parity $(P=0.90)$, maternal age $(P=0.85)$, and race $(P=0.58)$.

Contaminating fetal trophoblasts do not make AGT. Human decidua is a mixed tissue composed of maternal decidua and a few invading fetal placental cells called extravillous tro- phoblasts. If these contaminating fetal trophoblasts expressed AGT at high levels, our observation may have been artifactual.

We attempted to rule out this possibility by three separate methods. First, we genotyped the fetus and found no association between elevated T235 expression and fetal AGT genotype $(P=0.21)$ (Table II). Second, we tested decidua from 15 homozygous women carrying a known heterozygous fetus for contaminating fetal AGT transcript. We did not detect fetal AGT in any of the decidual samples from homozygous women (Fig. 8). Compared to the frequency of increased T235 levels observed in the heterozygous samples, the absence of contaminating fetal AGT in 15 homozygous samples is significant $(P<$ $0.05)$. Finally, we screened fetal trophoblasts for AGT expression in decidual sections showing AGT signal in the spiral arteries. We did not detect AGT signal in any of the fetal trophoblasts identified. These data suggest that elevated T235 levels in maternal decidua are not a consequence of contaminating fetal trophoblasts.

\section{Discussion}

AGT T235 expression is elevated in decidual spiral arteries. Spiral artery smooth muscle cells appear to be the source of AGT expression in first trimester decidua. We observed ele-
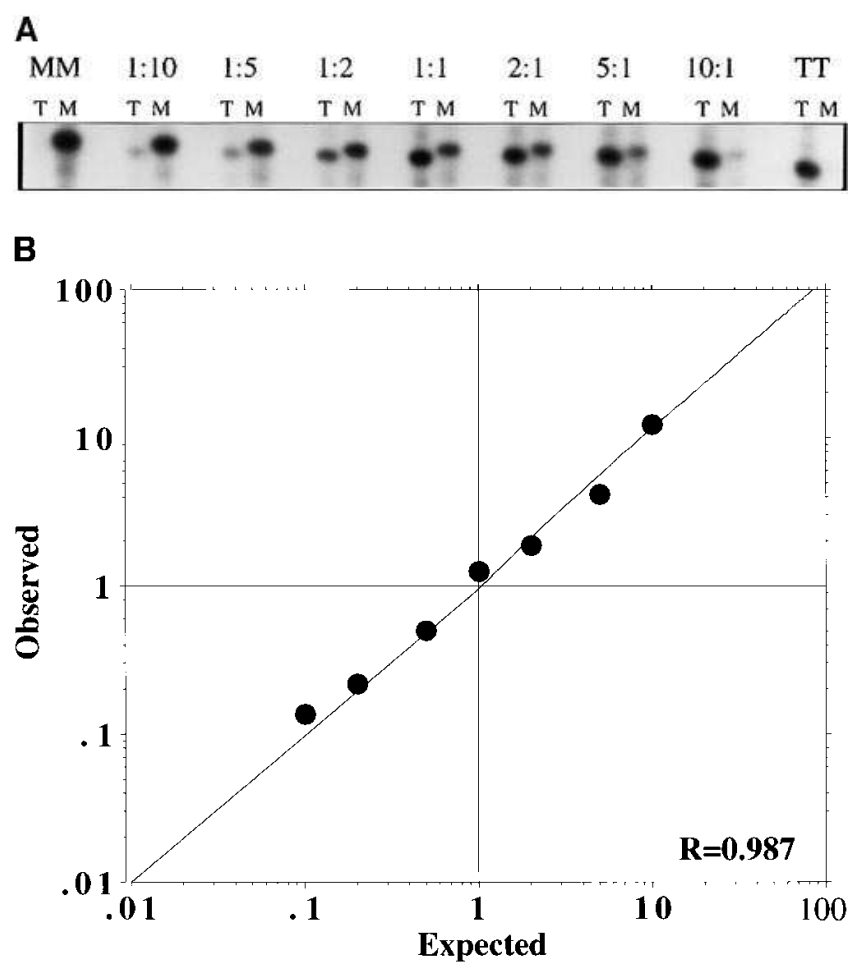

Figure 5. Allele-mixing analysis to determine the accuracy of the SNuPE assay. Defined amounts of RNA from two homozygous fetal liver samples (TT or MM at amino acid 235) were used as templates for RT-PCR amplification and subsequent SNuPE reactions. The expected T:M ratio is based on the relative amount of each allele added to the assay. $(A)$ The autoradiogram demonstrates that signal is a function of relative allele representation (T235:M235). (B) The regression plot below the autoradiogram shows the mean of three experiments. A strong positive correlation between the expected T235/ M235 ratio and the observed T235/M235 ratio $(r=0.987)$ demonstrates the accuracy of the SNuPE assay. 


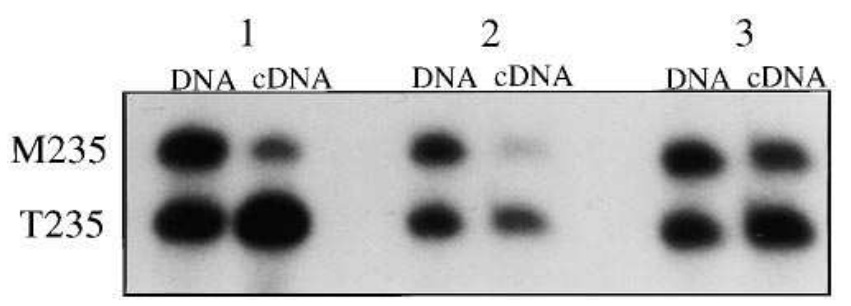

Figure 6. Autoradiogram of three decidual samples from heterozygous women tested using the allele-specific ligation assay. Genomic DNA controls exhibit equal allele-specific signal consistent with heterozygous DNA. Decidual cDNA samples 1 and 2 clearly demonstrate a greater than twofold difference in T235 signal when compared with M235 signal. While it is difficult to see the difference on the autoradiogram, densitometry reveals a twofold increase in T235 signal when compared with M235 signal in sample 3. These examples show the range of differences between first trimester decidual samples exhibiting clearly elevated T235 expression.

vated T235 expression compared to M235 levels in maternal decidua using both the allele-specific ligation assay and the single nucleotide primer extension assay. Together, these results suggest that T235 expression is elevated in the vessel wall.

We conclude that elevated T235 levels measured in the cDNA are due to true differences in allele-specific expression for three reasons. First, the allele-specific ligation assay and the SNuPE assay proved to be accurate and reproducible; moreover, results from these two methods showed a strong positive correlation. Second, the genomic DNA controls from each heterozygous decidual sample showed little departure from the expected 1:1 (T235:M235) ratio. Third, the most likely cause of false positive signal (invading fetal trophoblasts expressing AGT) was eliminated.

Heterogenous effects on allele-specific expression. Variation between individuals does not appear to be a result of the method used, or fetal contamination; therefore, we suspect that environmental or heterogenous effects have a role in mediating discrete differences between individuals. For example, since the decidual samples were obtained from disrupted tissue, we could not ascertain the exact location of the sample in relation to the invading placenta. Unfortunately, the sample location may be relevant, because the timing of spiral artery
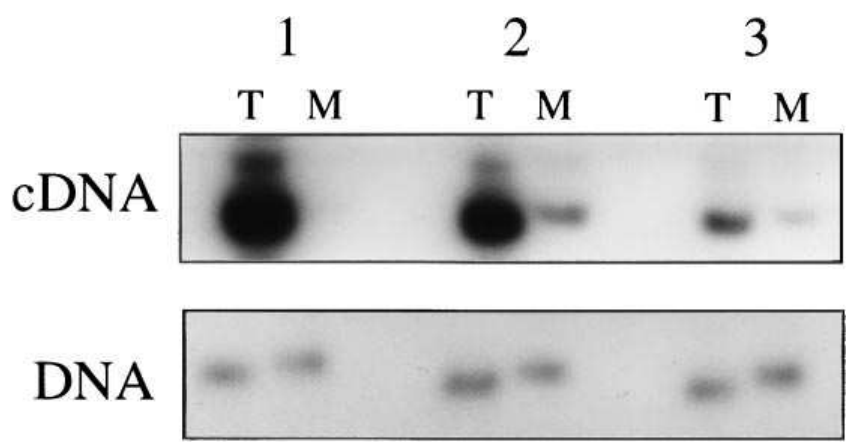

Figure 7. Autoradiogram of three decidual samples from heterozygous women tested using the SNuPE assay. Decidual cDNA samples clearly demonstrate at least a twofold difference in T235 signal when compared with M235 signal. Genomic DNA controls exhibit equal T235 and M235 signal.
Table I. Angiotensinogen T235 Expression is Elevated in First Trimester Decidua from Heterozygous Women

\begin{tabular}{ccccccc}
\hline & \multicolumn{2}{c}{ Ligation assay } & & \multicolumn{2}{c}{ SNuPE assay } \\
\cline { 2 - 3 } & Genomic & cDNA & & Genomic & cDNA \\
\hline $\begin{array}{c}\text { Relative allele representation } \\
\text { T235/M235 }\end{array}$ & 0.98 & 1.97 & & 1.32 & 2.53 \\
$( \pm$ SD $)$ & $(0.2)$ & $(2.0)^{*}$ & & $(0.4)$ & $(2.0)^{\ddagger}$
\end{tabular}

Relative allele representation in the genomic DNA and cDNA of first trimester decidual samples using the allele-specific ligation assay (ligation assay) and the SNuPE assay. Values are the means of 39 independent experiments performed in triplicate. Genomic DNA controls show the expected 1:1 ratio of T235:M235 signal. On average, both assays show a two-fold increase in T235 expression when compared with M235 levels in the cDNA. *Nonparametric analysis comparing the mean T/M ratio in the cDNA to the mean T/M ratio in the genomic DNA of each first trimester decidual sample demonstrates that T235 signal is significantly elevated compared to the M235 signal in heterozygous women $(P<0.0001)$. ${ }^{\ddagger}$ Nonparametric analysis comparing the mean $\mathrm{T} / \mathrm{M}$ ratio in the cDNA to the mean T/M ratio in the genomic DNA of each first trimester decidual sample demonstrates that T235 signal is significantly elevated compared to the M235 signal in heterozygous women $(P<0.01)$.

remodeling appears to be a function of proximity to the placental bed $(9,46)$. The variation between individuals may then be a function of differences in the percentage of spiral arteries at different stages of remodeling.

Loci modifying AGT expression could also have a role (4750). For example, AGT is an estrogen-responsive gene (50), and estrogen receptor expression is downregulated in decidual spiral artery smooth muscle cells during the first and early second trimesters (51). Local concentrations of estrogen may stimulate AGT expression in the spiral arteries, and downregulation of the estrogen receptor may play a role in mediating the disparity between T235 and M235 expression.

We tested the $\mathrm{C}(-20)$ promoter variant because it may alter a transcriptionally active cis-regulating sequence (52) that has a strong homology to an estrogen response element (25). If discrete factors are required to elevate relative T235 expression beyond the twofold threshold, the fact that $\mathrm{C}(-20)$ occurs

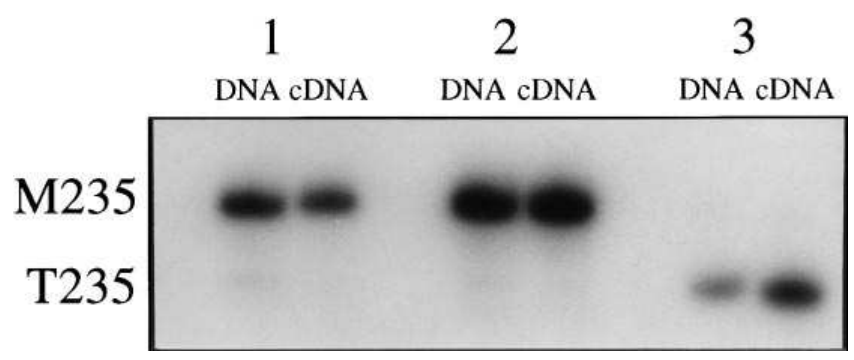

Figure 8. Autoradiogram of three decidual samples from homozygous women with a heterozygous fetus tested using the allele-specific ligation assay. Genomic DNA and cDNA from M235/M235 homozygous samples 1 and 2 show only the M235-specific product. There is no evidence of fetal T235 contamination. Similarly, sample 3 from a T235/T235 homozygous woman shows only the T235-specific product. Densitometry showed that fetal AGT contamination was undetectable over background in $15 / 15$ homozygous samples $(P<0.05)$. 
Table II. Characteristics of First Trimester Decidual Samples from Heterozygous Women

\begin{tabular}{|c|c|c|c|c|c|c|c|c|c|c|c|}
\hline \multirow{2}{*}{$\frac{\text { Sample }}{\text { No. }}$} & \multicolumn{2}{|c|}{ Ligation } & \multicolumn{2}{|c|}{ SNuPE } & \multicolumn{2}{|c|}{ Maternal genotype } & \multicolumn{2}{|c|}{ Fetal } & \multicolumn{3}{|c|}{ Maternal } \\
\hline & cDNA & DNA & cDNA* & DNA & $G(-6) A$ & $\mathrm{~A}(-20) \mathrm{C}$ & M235T & EGA & Parity & Age & Race \\
\hline 1 & 10.00 & 0.917 & 12.00 & 0.923 & $\mathrm{AG}$ & AA & & 10 & 3 & 30 & White \\
\hline 2 & 8.601 & 0.741 & 9.000 & 1.410 & $\mathrm{AG}$ & $\mathrm{AC}$ & TT & 10 & 2 & 21 & White \\
\hline 3 & 2.011 & 1.231 & 2.479 & 1.367 & $\mathrm{AG}$ & AA & $\mathrm{TM}$ & 11 & 4 & 24 & White \\
\hline 4 & 1.452 & 0.787 & 1.802 & 1.286 & $\mathrm{AG}$ & AA & $\mathrm{TM}$ & 8 & 1 & 24 & White \\
\hline 5 & 1.032 & 0.855 & 1.347 & 1.450 & AG & AA & MM & 6 & 1 & 23 & White \\
\hline 6 & 0.616 & 0.943 & 0.866 & 1.389 & $\mathrm{AG}$ & $\mathrm{AA}$ & & 6 & 1 & 22 & White \\
\hline 7 & 2.381 & 0.794 & 4.491 & 0.918 & $\mathrm{AG}$ & AA & $\mathrm{TM}$ & 8 & 4 & 31 & White \\
\hline 8 & 1.675 & 1.467 & 1.229 & 1.447 & $\mathrm{AG}$ & $\mathrm{AC}$ & $\mathrm{TM}$ & 5 & 6 & 26 & White \\
\hline 9 & 1.709 & 0.901 & 1.377 & 1.636 & $\mathrm{AG}$ & $\mathrm{AC}$ & & 8 & 2 & 24 & White \\
\hline 10 & 1.316 & 0.910 & 1.132 & 1.420 & $\mathrm{AG}$ & AA & MM & 6 & 3 & 27 & White \\
\hline 11 & 0.783 & 0.833 & 0.650 & 1.204 & $\mathrm{AG}$ & AA & $\mathrm{TM}$ & 10 & 5 & 38 & White \\
\hline 12 & 1.005 & 0.862 & 1.010 & 0.997 & $\mathrm{AG}$ & AA & $\mathrm{TM}$ & 7 & 1 & 24 & White \\
\hline 13 & 0.851 & 1.165 & 1.171 & 1.286 & $\mathrm{AG}$ & $\mathrm{AA}$ & TM & 12 & 8 & 41 & Asian \\
\hline 14 & 1.306 & 1.013 & 5.282 & 1.414 & $\mathrm{AG}$ & $\mathrm{AA}$ & & 5 & 1 & 16 & White \\
\hline 15 & 1.713 & 1.018 & 2.326 & 1.447 & $\mathrm{AG}$ & $\mathrm{CC}$ & $\mathrm{TT}$ & 7 & 1 & 25 & Asian \\
\hline 16 & 2.000 & 0.848 & 1.909 & 0.520 & $\mathrm{AG}$ & $\mathrm{AC}$ & $\mathrm{TT}$ & 7 & 1 & 22 & White \\
\hline 17 & 4.615 & 1.344 & 2.460 & 1.620 & $\mathrm{AG}$ & $\mathrm{AC}$ & & 6 & 1 & 19 & White \\
\hline 18 & 1.616 & 0.901 & 1.693 & 0.427 & $\mathrm{AG}$ & AA & TT & 9 & 1 & 14 & Hispanic \\
\hline 19 & 2.569 & 1.054 & 1.569 & 1.253 & $\mathrm{AG}$ & AA & TT & 10 & 1 & 14 & White \\
\hline 20 & 0.701 & 1.109 & 1.051 & 1.757 & $\mathrm{AG}$ & $\mathrm{AC}$ & TT & 7 & 1 & 23 & White \\
\hline 21 & 1.782 & 0.971 & 2.579 & 1.343 & $\mathrm{AG}$ & AA & TT & 11 & 1 & 23 & White \\
\hline 22 & 1.249 & 1.175 & 1.600 & 2.155 & $\mathrm{AG}$ & AA & $\mathrm{TM}$ & 8 & 1 & 32 & White \\
\hline 23 & 2.366 & 0.962 & 1.740 & 1.038 & $\mathrm{AG}$ & $\mathrm{AA}$ & $\mathrm{TM}$ & 6 & 1 & 28 & Asian \\
\hline 24 & 0.794 & 0.917 & 1.781 & 1.343 & $\mathrm{AG}$ & AA & TT & 7 & 3 & 24 & White \\
\hline 25 & 1.495 & 0.787 & 3.506 & 0.520 & $\mathrm{AG}$ & $\mathrm{AC}$ & TT & 7 & 3 & 25 & White \\
\hline 26 & 1.445 & 0.855 & 1.201 & 1.564 & $\mathrm{AG}$ & AA & $\mathrm{TM}$ & 13 & 2 & 29 & White \\
\hline 27 & 1.200 & 0.944 & 2.130 & 1.367 & $\mathrm{AG}$ & AA & $\mathrm{TM}$ & 11 & 1 & 17 & White \\
\hline 28 & 1.308 & 0.794 & 1.737 & 0.427 & $\mathrm{AG}$ & $\mathrm{AA}$ & $\mathrm{TM}$ & 8 & 5 & 32 & Hispanic \\
\hline 29 & 2.671 & 1.467 & 5.153 & 1.450 & $\mathrm{AG}$ & AA & TT & 9 & 6 & 30 & Black \\
\hline 30 & 0.712 & 0.741 & 1.283 & 1.389 & $\mathrm{AG}$ & $\mathrm{AA}$ & $\mathrm{TM}$ & 5 & 2 & 21 & White \\
\hline 31 & 1.027 & 0.901 & 1.411 & 1.367 & $\mathrm{AG}$ & $\mathrm{AA}$ & $\mathrm{TM}$ & 6 & 3 & 27 & White \\
\hline 32 & 3.088 & 0.909 & 4.871 & 1.140 & $\mathrm{AG}$ & $\mathrm{AC}$ & TM & 11 & 3 & 17 & White \\
\hline 33 & 1.004 & 0.833 & 1.994 & 1.636 & $\mathrm{AG}$ & $\mathrm{AC}$ & TM & 9 & 4 & 35 & White \\
\hline 34 & 0.934 & 0.862 & 1.025 & 1.420 & $\mathrm{AG}$ & AA & TM & 6 & 2 & 24 & White \\
\hline 35 & 1.350 & 1.165 & 2.927 & 1.204 & $\mathrm{AG}$ & AA & $\mathrm{TM}$ & 9 & 1 & 18 & White \\
\hline 36 & 1.145 & 1.013 & 3.172 & 0.832 & $\mathrm{AG}$ & $\mathrm{AC}$ & TT & 6 & 1 & 22 & White \\
\hline 37 & 1.882 & 1.428 & 3.929 & 1.757 & $\mathrm{AG}$ & $\mathrm{CC}$ & $\mathrm{TT}$ & 8 & 2 & 26 & White \\
\hline 38 & 1.021 & 0.962 & 1.292 & 1.644 & $\mathrm{AG}$ & AA & $\mathrm{TM}$ & 7 & 2 & 17 & White \\
\hline 39 & 0.811 & 0.840 & 1.435 & 2.544 & $\mathrm{AG}$ & AA & & 7 & 3 & 20 & White \\
\hline
\end{tabular}

EGA, estimated gestational age. Allele-specific ligation assay (ligation) and SNuPE assay values are reported as the means of the T235/M235 ratio from three experiments. ${ }^{*} \mathrm{SNuPE}$ assay results show a positive correlation with ligation assay results $(r=0.85, P<0.0001)$.

in a discrete subset of individuals with the T235 allele (40) may be relevant.

Biologic effects of elevated local angiotensin II production. It is difficult to prove that local angiotensin II production is elevated in vivo, because of the problem of discriminating between locally generated angiotensin II and angiotensin II derived from plasma. Alternatively, we can screen for biologic effects of elevated angiotensin II production. For example, since elevated local expression of AGT may cause atherotic changes (27-29, 33), we suspect that elevated angiotensinogen T235 expression may play a role in abnormal spiral artery remodeling associated with preeclampsia. We plan to test this hypothesis by comparing the frequency of abnormal spiral artery remodeling in women homozygous for the M235 allele to those carrying the T235 allele. Furthermore, in vitro studies using MM, TM, and TT vascular smooth muscle cell lines may provide additional data supporting or refuting our hypothesis.

Biologic effects of elevated T235 expression require further experimentation, but recent animal studies suggest that overexpression of maternal AGT may play a role in the pathogenesis of preeclampsia (53). Takimoto et al. recently showed that pregnant transgenic mice with the human AGT gene and a fetus with the human renin gene develop a preeclampsia-like syndrome. These transgenic mice overexpress both of these 
genes, but the location of AGT and renin expression appear to be important. Indeed, the syndrome did not develop when the mother expressed human renin and the fetus expressed human AGT. Our findings may provide a solution to this dilemma. We propose that the mechanism leading to preeclampsia is not the circulating RAS, but the local spiral artery RAS.

\section{Conclusions}

Our data suggest that angiotensinogen may function as part of a local RAS that has a role in spiral artery remodeling. The T235 association with preeclampsia may be a consequence of elevated local AGT expression in remodeling spiral arteries. Presumably, elevated local AGT expression leads to elevated local angiotensin II levels and abnormal pregnancy-induced remodeling of the uterine spiral arteries. Alternatively, women who are homozygous for the M235 allele have lower local AGT expression levels, permitting normal spiral artery remodeling in enough vessels that these women are less likely to develop preeclampsia.

It is possible that the T235-linked promoter mutation could also lead to elevated local AGT expression and abnormal remodeling in other human vessels. Whether elevated AGT expression could explain why the T235 allele is associated with essential hypertension (40), coronary atherosclerosis (54), and hypertensive diabetic nephropathy (55) remains to be determined.

\section{Acknowledgments}

We are grateful for the samples provided by the Utah Women's Clinic and the technical assistance of Katy Gestland and Ling Zhou.

This work was supported by a grant from The Willard L. Eccles Charitable Trust, a grant from the March of Dimes (\#6-FY95-0193), and a grant from the National Institutes of Health (1R01-HD 3217001). Jean-Marc Lalouel is an Investigator of the Howard Hughes Medical Institute. Kenneth Ward is an Investigator in the Eccles Program in Human Molecular Biology and Genetics.

\section{References}

1. Page, E. 1939. The relation between hydatid moles, relative ischemia of the gravid uterus and placental origin of preeclampsia. Am. J. Obstet. Gynecol. 37:291.

2. Redman, C. 1991. Current topics: preeclampsia and the placenta. Placenta. 12:301-308.

3. Bulfin, M., and P. Lawler. 1957. Problems associated with toxemia in twin pregnancies. Am. J. Obstet. Gynecol. 73:37-42.

4. Roberts, J. 1989. Pregnancy related hypertension. In Maternal Fetal Medicine: Principles and Practice. R. Resnik, editor. W.B. Saunders Company, Philadelphia. 777-823.

5. Tenney, B. 1940. Placenta in toxemia of pregnancy. Am. J. Obstet. Gynecol. 39:1000-1005.

6. Schweikhart, G., P. Kaufmann, and T. Beck. 1986. Morphology of placental villi after premature delivery and its clinical relevance. Arch. Gynecol. 239:101-114.

7. Gant, N. 1976. Metabolic clearance rate of dehydroisoandrosterone sulfate VI. Studies of eclampsia. Obstet. Gynecol. 47:327-330.

8. Roberts, J., R. Taylor, T. Musci, G. Rodgers, C. Hubel, and M. McLaughlin. 1989. Preeclampsia: an endothelial cell disorder. Am. J. Obstet. Gynecol. 161:1200-1204.

9. Brosens, I., W. Robertson, and H. Dixon. 1967. The physiological response of the vessels of the placental bed to normal pregnancy. J. Pathol. Bacteriol. 93:569-579.

10. Zeek, P., and N. Assali. 1950. Vascular changes in the decidua associated with eclamptogenic toxemia. Am. J. Clin. Pathol. 20:1099.

11. Brosens, I., W. Robertson, and H. Dixon. 1972. The role of the spiral arteries in the pathogenesis of preeclampsia. Obstet. Gynecol. Annu. 1:177-191.

12. Pijnenborg, R., J. Anthony, D. Davey, A. Rees, A. Tiltman, L. Ver- cruysse, and A. Assche. 1991. Placental bed spiral arteries in the hypertensive disorders of pregnancy. Br. J. Obstet. Gynaecol. 98:648-655.

13. Pijnenborg, R., G. Dixon, W. Robertson, and I. Brosens. 1980. Trophoblastic invasion of human decidua from 8 to 18 wks of pregnancy. Placenta. 1:319.

14. Pijnenborg, R., W. Robertson, I. Brosens, and G. Dixon, 1981. Trophoblast invasion and the establishment of hemochorial placentation in man and laboratory animals. Placenta. 2:71-92.

15. North, R., C. Ferrier, D. Long, K. Townend, and P. Kincaid-Smith 1994. Uterine artery doppler flow velocity waveforms in the second trimester for the prediction of preeclampsia and fetal growth retardation. Obstet. Gynecol. 83:378-386.

16. Zamudio, S., S. Palmer, T. Dahms, J. Berman, D. Young, and L. Moore. 1995. Alterations in uteroplacental blood flow precede hypertension in preeclampsia at high altitude. J. Appl. Physiol. 79:15-22.

17. Nadji, P., and S. Sommers. 1973. Lesions of toxemia in first trimester pregnancies. Am. J. Clin. Pathol. 59:344-349.

18. Lichtig, C., M. Deutch, and J. Brandes. 1984. Vascular changes of endometrium in early pregnancy. Am. J. Clin. Pathol. 81:702-707.

19. Chesley, L., R. Cosgrove, and J. Annitto. 1961. Pregnancy in sisters and daughters of eclamptic women. Pathol. Microbiol. 24:662-666.

20. Arngrimsson, R., H. Bjornsson, and R. Geirsson. 1995. Analysis of different inheritance patterns in preeclampsia/eclampsia syndrome. Hypertension in Pregnancy. 14:27-38.

21. Ward, K., A. Hata, X. Jeunemaitre, C. Helin, L. Nelson, C. Namikawa, P. Farrington, M. Ogasawara, K. Suzumori, S. Tomoda, et al. 1993. A molecular variant of angiotensinogen associated with preeclampsia. Nat. Genet. 4:59-61.

22. Arngrimsson, R., S. Purandare, M. Conner, J. Walke, S. Bjornssen, F. Soubrier, Y. Kotelevtsev, R. Geirsson, and H. Bjornsson. 1993. Angiotensinogen: a candidate gene involved in preeclampsia? Nat. Genet. 4:114-115.

23. Kobashi, G. 1995. A case-control study of pregnancy-induced hypertension with a genetic predisposition: association of a molecular variant of angiotensinogen in the Japanese women. Hok Ig Zasshi. 70:649-657.

24. Morgan, L., P. Baker, F.B. Pipkin, and N. Kalsheker. 1995. Pre-eclampsia and the angiotensin gene. Br. J. Obstet. Gynaecol. 102:489-490.

25. Inoue, I., T. Nakajima, C. Williams, J. Quackenbush, R. Puryear, M Powers, T. Cheng, E. Ludwig, A. Sharma, A. Hata, et al. 1997. A nucleotide substitution in the promoter of human angiotensinogen is associated with essential hypertension and affects basal transcription in vitro. J. Clin. Invest. 99: 1786-1797.

26. Campbell, D. 1987. Circulating and Tissue Angiotensin Systems. J. Clin. Invest. 79:1-6.

27. Powell, J., J.-P. Clozel, R. Muller, H. Kuhn, F. Hefti, M. Hosang, and H. Baumbartner. 1989. Inhibitors of angiotensin-converting enzyme prevent myointimal proliferation after vascular injury. Science (Wash. DC). 245:186-188.

28. Naftilian, A., W. Zuo, J. Ingelfinger, T. Ryan, R. Pratt, and V. Dzau. 1991. Localization and differential regulation of angiotensinogen mRNA expression in the vessel wall. J. Clin. Invest. 87:1300-1311.

29. Dzau, V. 1984. Vascular renin-angiotensin: a possible autocrine or paracrine system in control of vascular function. J. Cardiovas. Pharm. 6:377s-382s.

30. Berk, B., V. Vekshtein, H. Gordon, and T. Tsuda. 1989. Angiotensin IIstimulated protein synthesis in cultured vascular smooth muscle cells. Hypertension (NY). 13:305-314.

31. Naftilan, A., R. Pratt, and V. Dzau. 1989. Induction of platelet-derived growth factor A-chain and $c-m y c$ gene expressions by angiotensin II in cultured rat vascular smooth muscle cells. J. Clin. Invest. 83:1419-1424.

32. Dzau, V., G. Gibbons, and R. Pratt. 1991. Molecular mechanisms of vascular renin-angiotensin system in myointimal hyperplasia. Hypertension (NY). 18:II100-II105.

33. Poulsen, K. 1973. Kinetics of the renin system. The basis for determination of the different components of the system. Scand. J. Clin. Lab. Invest. 31:186.

34. Nuovo, G. 1995. In situ PCR: protocols and applications. PCR Methods and Applications. 4:151s-167s.

35. Powell, S., G. Petersen, A. Krush, S. Booker, J. Jen, F. Giardiello, S Hamilton, B. Vogelstein, and K. Kinzler. 1993. Molecular diagnosis of familial adenomatous polyposis. N. Engl. J. Med. 329:1982-1987.

36. Singer-Sam, J., and A. Riggs. 1993. Quantitative analysis of messenger RNA levels: reverse transcription-polymerase chain reaction single nucleotide primer extension assay. Methods Enzymol. 225:344-351.

37. Wilcox, J. 1993. Fundamental principles of in situ hybridization. J. Histochem. Cytochem. 41:1725-1733.

38. Allen, T. 1994. Hematoxylin and Eosin. Lab. Meth. Histotech. 53-56.

39. Chomczynski, P. 1993. A reagent for the single-step simultaneous isolation of RNA, DNA and proteins from cell and tissue samples. Biotechniques. 15:532-537.

40. Jeunemaitre, X., and J.-M. Lalouel. 1992. Molecular basis of human hypertension: role of angiotensinogen. Cell. 71:169-180.

41. Rust, S., H. Funke, and G. Assmann. 1993. Mutagenically separated PCR (MS-PCR): a highly specific one step procedure for easy mutation detection. Nucl. Acids Res. 21:3623-3629.

42. Gaillard, I., E. Clauser, and P. Corvol. 1989. Structure of the human an- 
giotensinogen gene. DNA (NY). 8:87-99.

43. Labarrere, C., and W. Faulk. 1994. Antigenic identification of cells in spiral artery trophoblastic invasion: Validation of histologic studies by tripleantibody immunohistochemistry. Am. J. Obstet. Gynecol. 171:165-171.

44. Rosner, B. 1990. Fundamentals of Biostatistics. 3rd ed. M. Payne, editor. PWS-Kent, Boston, MA. 651.

45. Paul, M., J. Wagner, and V. Dzau. 1993. Gene expression of the reninangiotensin system in human tissues. J. Clin. Invest. 91:2058-2064.

46. Pijnenborg, R., J. Bland, W. Robertson, and I. Brosens. 1983. Uteroplacental arterial changes related to interstitial trophoblast migration in early human pregnancy. Placenta. 4:397-414.

47. Tewksbury, D. 1983. Angiotensinogen. Fed. Proc. 42:2724-2728.

48. Menard, J., J. Bouhnik, E. Clauser, J. Richoux, and P. Corvol. 1983. Biochemistry and regulation of angiotensinogen. Clin. Exp. Hypertension. A5: 1005-1019.

49. Alhenc-Gelas, F., J. Richard, D. Courbon, J. Warnet, and P. Corvol. 1991. Distribution of plasma angiotensin I-converting enzyme levels in healthy men: relationship to environmental and hormonal parameters. J. Lab. Clin. Med. 117:33-39.
50. Fukamizu, A., S. Takahashi, M.S. Seo, M. Tada, K. Takimoto, S. Uehara, and K. Murakami. 1990. Structure and expression of the human angiotensinogen gene. J. Biol. Chem. 265:7576-7582.

51. Perrot-Applanat, M., M. Deng, H. Fernandez, C. Lelaidier, G. Meduri, and P. Bouchard. 1994. Immunohistochemical localization of estradiol and progesterone receptors in human uterus throughout pregnancy: expression in endometrial blood vessels. J. Clin. Endocrinol. Metab. 78:216-224.

52. Yanai, K. 1996. A cis-acting DNA element located between TATA box and transcription initiation site is critical in response to regulatory sequence in human angiotensinogen gene. J. Biol. Chem. 271:15981-15986.

53. Takimoto, E., J. Ishida, F. Sugiyama, H. Horiguchi, K. Murakami, and A. Fukamizu. 1996. Hypertension induced in pregnant mice by placental renin and maternal angiotensinogen. Science (Wash. DC). 274:995-997.

54. Ishigami, T. 1995. Molecular variant of angiotensinogen gene is associated with coronary atherosclerosis. Circulation. 91:951-954.

55. Tarnow, L., F. Cambien, P. Rossing, F. Nielsen, B. Hansen, S. Ricard, O. Poirier, and H.-H. Parving. 1996. Angiotensinogen gene polymorphisms in IDDM patients with diabetic nephropathy. Diabetes. 45:367-369. 